University of Tennessee Health Science Center UTHSC Digital Commons

Spring 4-2019

\title{
Implementation of Pharmacogenomics into Electronic Health Record and Clinical Decision Support
}

\author{
Dharaben Naik \\ University of Tennessee Health Science Center
}

Follow this and additional works at: https://dc.uthsc.edu/hiimappliedresearch

Part of the Health and Medical Administration Commons, and the Health Information Technology Commons

\section{Recommended Citation}

Naik, Dharaben, "Implementation of Pharmacogenomics into Electronic Health Record and Clinical Decision Support" (2019). Applied Research Projects. 60. . https://doi.org/10.21007/chp.hiim.0063 https://dc.uthsc.edu/hiimappliedresearch/60

This Research Project is brought to you for free and open access by the Department of Health Informatics and Information Management at UTHSC Digital Commons. It has been accepted for inclusion in Applied Research Projects by an authorized administrator of UTHSC Digital Commons. For more information, please contact jwelch30@uthsc.edu. 
Implementation of Pharmacogenomics into Electronic Health Record and Clinical Decision Support

\section{Dhara Naik}

The University of Tennessee Health Science Center

Department of Health Informatics \& Information Management

Advisor: Sajeesh Kumar, $\mathrm{PhD}$ 


\begin{abstract}
The advent of electronic health records (EHR) and clinical decision support (CDS) has brought numerous changes in the healthcare field and has improved how patients receive care. The field of pharmacogenomics has made many breakthrough discoveries in the last few decades and these new advances have immensely reduced the cost of genetic testing. As advances have been made, researchers have discovered that individuals may respond to a medication differently due to genetic variants. There is a shift in the medical field from a one size fits all model to a personalized medicine model based on genetic information. Institutions have started to incorporate genetic information in their EHR and CDS systems to aid clinicians in the prescribing process. The rate of implementation is uneven among the institutions across the United States. Healthcare institutions have encountered some challenges associated with implementing pharmacogenomic data into CDS and EHR system. These challenges include lack of clinician education about pharmacogenomic data, poor user interface, and lack of resources for additional information for these alerts. If these challenges are overcome, there is great potential for pharmacogenomic CDS systems to help improve patient care and reduce adverse drug events.
\end{abstract}




\section{Table of Contents}

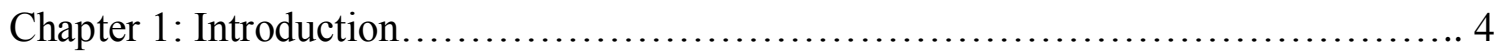

Chapter 2: Review of Literature.......................................... 8

Chapter 3: Results.....................................................13

Chapter 4: Discussion........................................................... 19

Chapter 5: Conclusion \& Recommendations.................................21

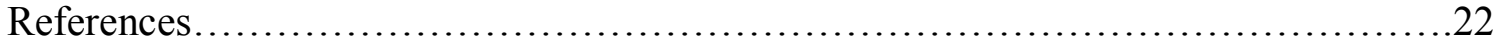

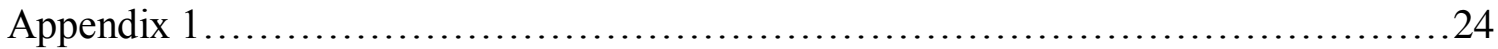

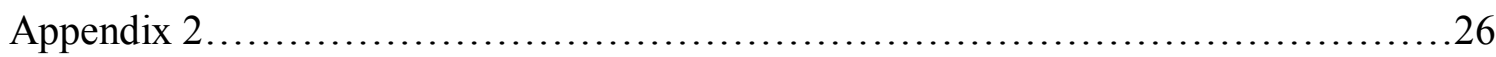

\section{List of Tables and Figures}

Table 1 - Comparison of Reviewed Studies

Table 2 - Search Queries

Figure 1 - Flowchart of Literature Search Results 


\section{Implementation of Pharmacy Informatics}

\section{Chapter 1}

\section{Introduction}

Health informatics has rapidly advanced in the last several decades and there has been tremendous growth in the field. The U.S. National Library of Medicine as define health informatics as an "interdisciplinary study of the design, development, adoption, and application of IT-based innovations in healthcare services delivery, management, and planning" (HIMSS, 2014). There are several subdivisions of health informatics such as pharmacy informatics and nursing informatics. Health informatics and associated fields are currently being utilized in a variety of ways to provide a high level of patient care and improve outcomes. For example, a large number of hospitals in the United States now utilize automated dispensing cabinets to dispense medications in inpatient and outpatient pharmacies. The utilization of computerized physician order entry (CPOE) system is also on the rise. These systems and many other systems like it require health informatics to utilize them to their full potential.

\section{Background of Problem}

Numerous new technologies have been introduced in the healthcare field, and there has been a shift in the healthcare world from a "one size fits all model to a precision personalized regimen" (Klein, 2017). The Human Genome Project, which was conducted to map and understand all of the genes of human beings, gave researchers an insight into human genetic information (NIH, 2018). As technology and science advanced, over the years, scientists discovered that some medications effect patients differently. Advancements in genetics research revealed that patients metabolize medications differently based on their genetic makeup. A medication that has gone through rigorous clinical trials can still cause adverse drug reactions 
(ADRs) in a certain patient population. These varying responses to drugs are typically due to genetic variations. There are two types of genetics variations, inherited variants and acquired variants (Ko, 2016). The inherited variants that encode drug-metabolizing enzymes, drug transporters, drug targets, and human-leukocyte antigen (HLA) can affect individual response to medication can impact how individual patients respond to certain medications. The acquired mutations are associated with the development or progression, and they can "affect the drug response of tumors that carry specific mutations, so called target therapy" (Ko, 2016).

Pharmacogenomics is the utilization of "current technology for precise determination of genetic variants influence drug response, and to develop personalized strategies that maximize therapeutic efficacy and assure drug safety" (Ko, 2016). Many large-scale genome-wide studies have helped increase our understanding of the underlying mechanism of drug efficacy and ADRs. Pharmacogenomics "is the driving force behind" the precision medication therapeutic approach (Klein, 2017). Clinicians can utilize pharmacogenomics data to improve the clinical outcomes of pharmacotherapy. For example, warfarin, which is an anticoagulation medication, has been observed to be altered by two different genetic variations. Clinicians can utilize the genetic information of a patient in regards to warfarin dosing to improve the initial dosing of the medication and ensure that the patient does not have bleeding complications due to this medication. Patient genetic data can be utilized to improve prescribing practices for many other medications. The adoption and implementation of pharmacogenomics has been slow in institutions in the United States. Pharmacogenomics can help decrease healthcare costs by decreasing the number of adverse drug reactions and improve patient care by potentially allowing providers to prescribe medications with a patient's genetic data in mind.

\section{Purpose of the Study}


Various advances have been made in the informatics field as well as the pharmacogenomics field. Many healthcare organizations in the United States are obtaining genetic information and utilizing that information in various ways. Some electronic health record (EHR) systems are capable of integrating genomic data and using clinical decision support (CDS) systems, however, there are many institutions that have not begun integrating genetic information into an EHR system or the EHR system is not capable of integrating the genomic data. The number of institutions utilizing pharmacogenomics data is increasing, however, their approach to implementation of pharmacogenomics data varies across the board. The adoption of pharmacogenomic CDS system integrated into an EHR system is currently largely limited to large academic centers. The purpose of this study is to summarize the literature describing implementation and utilization of pharmacogenomic information into electronic health records and clinical decision support.

\section{Significance of the Study}

As advances in medications and pharmacogenomics occur, there will be a shift from a one size fits all to a personalized medication approach. Healthcare institutions are moving towards utilizing genomic data to provide better patient care. There are some institutions that are currently utilizing pharmacogenomic information when prescribing certain medications, however, the number of institutions implementing pharmacogenomic information into EHR and CDS will increase over the years. For example, in oncology, genomic data is becoming important for prescribing a treatment regimen because certain cancers respond to specific treatments if they have that genomic variation, or the cancer may not respond to certain therapies because of the variation. The genomic data of these patients needs to be incorporated into the EHR system to allow clinicians to make appropriate decisions for their patients and provide 
better patient care. These advancements will aid in providing high-quality of care to patients.

\section{Research Questions}

The objective of this paper is to determine how pharmacogenomics data is being implemented into EHR and CDS systems. How are institutions implementing pharmacogenomic data into their EHR and CDS systems? How is this implementation changing prescribing practice?

\section{Definition of Terms}

Electronic Health Records (EHR) - an electronic version of a patient's paper chart which includes diagnosis, medication history, treatment histories, their clinical laboratory data, and a wide variety of other information.

Clinical Decision Support (CDS) - provides clinicians, staff, patients, and others involved in the care with knowledge and patient-specific information to improve health and health care.

Computerized Physician Order Entry (CPOE) - providers use a computer application to enter and send treatment instructions such as laboratory and medication orders.

Pharmacogenomics (PGx) - study of how genes affect an individual's response to drugs.

Adverse Drug Reaction (ADR) - the unwanted and undesired effects of a medication.

\section{Limitations}

The collection, implementation, and utilization of pharmacogenomic data has started to increase, however, there are still many organizations that do not follow this practice. The limitation of the study is that only a small number of institutions have fully implemented pharmacogenomic data in their EHR system and are utilizing that data with their CDS system to make changes in prescribing practices at those institutions. The implementation of such system is also concentrated in large academic systems, which does not provide the full viewpoint of the impact of utilizing a pharmacogenomic CDS system with an EHR system. There are still some institutions that have not adopted a complete EHR system. There is limited data on the impact of the implementation of Pharmacogenomics data into EHR and CDS systems. 


\section{Chapter 2}

\section{Review of Literature}

\section{Introduction}

Healthcare in the United States has seen drastic changes over the years. One major change that is seen at most institutions is the use of information technology. The growing use of information technology has led to the development of several branches in health informatics such as pharmacy informatics and nursing informatics. The advancements in informatics and information technology has increased the utilization of new technologies such as electronic health records (EHR) and computerized physician order entry (CPOE) system. The adoption of and EHR system has increased in healthcare institutions in the United States. These changes have helped institutions improve patient care.

For years, there has been a view of a one size fits all model with drug therapy for patients. With the advent of new technology, there has been a push towards personalized medicine. The ultimate result of personalized medicine would be increased quality and safety of care for patients. This systemic literature review is an effort to determine the implementation of pharmacogenomics data into electronic health records at healthcare institutions across the United States and determine whether prescribing practices have changed as a result of such implementation.

\section{Method}

The literature review was conducted using several electronic sources such as PubMed, Scopus, and the Web of Science. Various search terms were used to identify relevant articles such as electronic health records, electronic medical records, and pharmacogenomics. A Medical Subject Headings (MeSH) search was conducted on PubMed using "Electronic health records." 
The MeSH terms were then used to build a search query, which yielded 34,391 articles. Another MeSH term search was conducted using the search terms "Medical Records System." The results of the MeSH search were utilized to build a search query, which yielded 38,856 . The above queries were combined together, which resulted in 20,144 articles. A MeSH search was conducted utilizing the term pharmacogenomics, and a search query was conducted utilizing the MeSH search results, which generated 26,748 articles. The results of the "Electronic Health Records," "Medical Records System," and "Pharmacogenomics" were combined to refine the search query, which resulted in 113 articles. The search was further limited to articles from the last 5 years, which narrowed the search to 65 articles. The same search query that was used in PubMed was utilized in Scopus and Web of Science, which resulted in 81 and 1 articles respectively. The total number of articles obtained from all three databases was 147 articles. After duplicates were removed, there were a total of 140 articles remaining for this review.

Another search MeSH search was conducted utilizing the term Clinical Decision Support, which was then used to build a search query, which resulted in 52,968 articles. This search query was combined with the previous queries, and it resulted in 51 articles. The search was then limited to articles from the last 5 years, which narrowed the search to 46 articles. The literature articles utilized in this review discuss the implementation of pharmacogenomic information in electronic health records and clinical decision support systems. in hospitals in the United States.

\section{Inclusion Criteria}

The article was included if it contained any of the following:

1. Published in the last 5 years

2. The article discussed utilizing pharmacogenomic data by implementing them into EHR and CDS system

3. Article was published in the United States 


\section{Exclusion Criteria}

The article was excluded if it contained any of the following:

1. The article was not a research article such as an editorial, case study, comment piece, and book section

2. The article was published in a language other than English

3. The article was published outside of the United States

Eligibility of the articles was initially determined based on the title and abstracts. Once it was determined that the article met the inclusion criteria, full text articles were retrieved and studied to determine their relevance. This search generated 10 articles that were relevant to the topic of this literature review. Similar steps were followed to narrow the results of the second search. Duplicates that were a part of the previous queries were removed and the remaining articles were analyzed for this literature review, which resulted in a total of 3 additional articles because majority of the articles were duplicates from the previous search query. Articles were included and excluded if they did not meet the above inclusion criteria (Figure 1, Appendix 1). After careful review, the search was narrowed to 13 articles (Table 1).

\section{Population Studied}

The articles chosen for this review had different types of populations that were studied. Some articles studied prescribers and their response to employing pharmacogenomic information with CDS while prescribing medications. For example, Devine et al presented clinicians with hypothetical clinical scenarios and studied their prescribing practice based on the pharmacogenomic data that was presented (Devine et al., 2014). Some articles studied the EHR and CDS systems that presented the pharmacogenomic data to determine challenges in implementing such systems and find potential solutions to tackle these challenges (Rosenman, 2017).

\section{Survey Method}


There were many different survey methods utilized in the articles that were a part of this review. Some studies utilized hypothetical clinical case scenarios to determine response of prescribers to gene-drug pair that might require dosage adjustment. Some studies collected data over a period of time to determine how many CDS alerts were generated and if those alerts led clinicians to make changes in their prescribing practice. For example, Ubanyionwu et al studied prescriber's response to CDS alerts that were designed to prompt testing for a TPMT genetic variance. Some studies sent surveys to providers to evaluate prescriber perspective on the implementation and usefulness of pharmacogenomic testing in clinical practice.

\begin{tabular}{|c|c|c|c|}
\hline $\begin{array}{l}\text { Author, } \\
\text { Year }\end{array}$ & Objective, Participant & Study Method & Results \\
\hline $\begin{array}{l}\text { Ubanyionwu } \\
\text { et al. (2018) }\end{array}$ & $\begin{array}{l}\text { Single-center, } \\
\text { retrospective, chart- } \\
\text { review }\end{array}$ & $\begin{array}{l}\text { Prescriber's response } \\
\text { Clinical Decision Support } \\
\text { (CDS) alert designed to } \\
\text { prompt TPMT testing }\end{array}$ & $\begin{array}{l}\text { 9-month study period: } 500 \text { CDS alerts } \\
\text { generated: TPMT testing ordered in } \\
20 \% \text { of the cases; TPMT phenotyping } \\
\text { not ordered in } 80 \% \text { of the cases }\end{array}$ \\
\hline $\begin{array}{l}\text { Caraballo et } \\
\text { al. (2017) }\end{array}$ & $\begin{array}{l}\text { Overcome challenges } \\
\text { of PGx implementation } \\
\text { with comprehensive } \\
\text { and systematic } \\
\text { implementation model }\end{array}$ & $\begin{array}{l}\text { Development and } \\
\text { implementation of PGx } \\
\text { organized into } 8 \\
\text { interdependent components; } \\
\text { aspects of implementation } \\
\text { were assessed }\end{array}$ & $\begin{array}{l}18 \text { drug-gene drug interactions } \\
\text { implemented in EHR; complete } \\
\text { adherence to the model; } \\
\text { implementation impacted } \\
\text { approximately } 1,247 \text { providers and } \\
3,788 \text { patients }\end{array}$ \\
\hline $\begin{array}{l}\text { Hicks et al. } \\
\text { (2016) }\end{array}$ & $\begin{array}{l}\text { Development of } \\
\text { pharmacist-managed } \\
\text { pharmacogenomic } \\
\text { services }\end{array}$ & $\begin{array}{l}\text { CPIC guidelines for various } \\
\text { drug-gene pairs were } \\
\text { integrated into patient care; } \\
\text { custom rules and alerts were } \\
\text { developed and deployed to } \\
\text { EHR for providing } \\
\text { pharmacogenomic decision } \\
\text { support }\end{array}$ & $\begin{array}{l}\text { Integrating just } 3 \text { genes over a } 3 \text { - } \\
\text { month period identified } 17 \text { patients at } \\
\text { risk for severe adverse reactions, and } \\
\text { resulted in reduction of } \\
\text { pharmacotherapy to reduce the risk of } \\
\text { adverse events }\end{array}$ \\
\hline $\begin{array}{l}\text { Manzi et al. } \\
(2016)\end{array}$ & $\begin{array}{l}\text { Implementation of a } \\
\text { comprehensive clinical } \\
\text { PGx service }\end{array}$ & $\begin{array}{l}\text { CDS for medication ordering } \\
\text { and dispensing driven by } \\
\text { documented PGx variant } \\
\text { status in EHR; }\end{array}$ & $\begin{array}{l}\text { CDS provided guidance to providers } \\
\text { for } 31 \text { patients with actionable PGx } \\
\text { variants }\end{array}$ \\
\hline $\begin{array}{l}\text { St Sauver et } \\
\text { al. (2016) }\end{array}$ & $\begin{array}{l}\text { Provider response to } \\
\text { PGx CDS alerts } \\
\text { integration into EHR }\end{array}$ & $\begin{array}{l}159 \text { clinicians were sent an } \\
\text { e-mail survey to understand } \\
\text { perspectives on the } \\
\text { implementation and use of } \\
\text { PGx testing in clinical } \\
\text { practice }\end{array}$ & $\begin{array}{l}\text { Survey response rate }=57 \% ; 52 \% \text { did } \\
\text { not expect to use or did not know } \\
\text { whether they would use PGx } \\
\text { information in future prescribing } \\
\text { practices; 53\% of the clinicians felt } \\
\text { alerts were confusing, irritating, } \\
\text { frustrating, or difficult to find } \\
\text { additional information; } 30 \% \text { of the } \\
\text { providers that received a CDS alert } \\
\text { changed their prescription to an }\end{array}$ \\
\hline
\end{tabular}




\begin{tabular}{|c|c|c|c|}
\hline & & & alternative medication \\
\hline $\begin{array}{l}\text { Nishimura et } \\
\text { al. (2016) }\end{array}$ & $\begin{array}{l}\text { Create proof-of-concept } \\
\text { decision support alert } \\
\text { system generated from } \\
\text { PGx incidental findings }\end{array}$ & $\begin{array}{l}\text { Decision support rules using } \\
\text { discrete, machine-readable } \\
\text { incidental finding results } \\
\text { programmed into an EHR } \\
\text { system }\end{array}$ & $\begin{array}{l}\text { Alerts for } 48 \text { pharmacogenomic } \\
\text { variants created; } 94 \text { participants } \\
\text { enrolled in the study, with } 49 \\
\text { participants having one or more PGx } \\
\text { variant identified }\end{array}$ \\
\hline $\begin{array}{l}\text { Overby et al. } \\
(2015)\end{array}$ & $\begin{array}{l}\text { Determine clinical } \\
\text { impact of CDS system } \\
\text { embedded in EHR to } \\
\text { deliver PGx } \\
\text { information to } \\
\text { physicians }\end{array}$ & $\begin{array}{l}22 \text { physicians participated in } \\
\text { the study; physicians } \\
\text { performed prescribing tasks } \\
\text { utilizing simulated clinical } \\
\text { case scenarios }\end{array}$ & $\begin{array}{l}83 \% \text { of physicians saw an advantage } \\
\text { using PGx-CDS at the start of the } \\
\text { study and } 94 \% \text { at the end of the study; }\end{array}$ \\
\hline $\begin{array}{l}\text { Nishimura et } \\
\text { al. (2015) }\end{array}$ & $\begin{array}{l}\text { Determine if physicians } \\
\text { find CDS alerts for } \\
\text { PGx drug-gene } \\
\text { interactions useful and } \\
\text { assess perceptions of } \\
\text { usability }\end{array}$ & $\begin{array}{l}52 \text { physicians participated in } \\
\text { an online simulation and } \\
\text { questionnaire involving a } \\
\text { prototype alert for } \\
\text { clopidogrel and CYP2C19 }\end{array}$ & $\begin{array}{l}4 \% \text { of participants said they would } \\
\text { override alert; } 92 \% \text { agreed alerts were } \\
\text { useful; } 87 \% \text { found visual interface } \\
\text { appropriate; } 91 \% \text { felt timing of alert } \\
\text { appropriate; and } 75 \% \text { unfamiliar with } \\
\text { specific drug-gene interaction; } 80 \% \\
\text { preferred ability to order the } \\
\text { recommended medication within the } \\
\text { alert }\end{array}$ \\
\hline $\begin{array}{l}\text { Devine et al. } \\
\text { (2014) }\end{array}$ & $\begin{array}{l}\text { Evaluate a CPOE } \\
\text { system with PGx-CDS } \\
\text { alerts in a simulated } \\
\text { environment }\end{array}$ & $\begin{array}{l}\text { Presented } 7 \text { cardiologists and } \\
3 \text { oncologists with five } \\
\text { hypothetical clinical case } \\
\text { scenarios }\end{array}$ & $\begin{array}{l}\text { Participants considered PGx } \\
\text { information important for prescribing } \\
\text { decisions, but the information needs } \\
\text { to be presented in a relevant and } \\
\text { useful manner }\end{array}$ \\
\hline $\begin{array}{l}\text { Rosenman et } \\
\text { al. (2017) }\end{array}$ & $\begin{array}{l}\text { Describe challenges } \\
\text { and potential solutions } \\
\text { of implementing } \\
\text { programs to support } \\
\text { precision medicine }\end{array}$ & $\begin{array}{l}\text { Descriptive case study of } \\
\text { implementation of } \\
\text { pharmacogenomics program } \\
\text { in an urban safety-net } \\
\text { hospital and its outpatient } \\
\text { clinics }\end{array}$ & $\begin{array}{l}\text { There is strong potential for PGx to } \\
\text { improve health and heath care and be } \\
\text { cost-effective, but there are many } \\
\text { challenges that need to be addressed } \\
\text { when bringing PGx into wider use }\end{array}$ \\
\hline $\begin{array}{l}\text { Caraballo et } \\
\text { al. }(2015)\end{array}$ & $\begin{array}{l}\text { Clinical decision } \\
\text { support to implement } \\
\text { CYP2D6 Drug-Gene } \\
\text { Interaction }\end{array}$ & $\begin{array}{l}\text { Developed CDS rules to alert } \\
\text { prescribers based on PGx } \\
\text { results for CYP2D6 and } \\
\text { documentation of phenotype } \\
\text { and genotypes in the EHR }\end{array}$ & $\begin{array}{l}\text { Total of } 206 \text { events triggered over } \\
\text { study period; } 45 \% \text { were unreadable; } \\
\text { implementation of CDS integrated in } \\
\text { EHR is feasible, but significant } \\
\text { challenges are present }\end{array}$ \\
\hline $\begin{array}{l}\text { Danahey et } \\
\text { al. (2017) }\end{array}$ & $\begin{array}{l}\text { Build and design a } \\
\text { user-friendly Genomic } \\
\text { Prescribing System } \\
\text { (GPS) }\end{array}$ & $\begin{array}{l}\text { PGx information was } \\
\text { collected and external data } \\
\text { sets were integrated to build } \\
\text { the Genomic Prescribing } \\
\text { System }\end{array}$ & $\begin{array}{l}\text { The GPS had } 257 \text { CDS encompassing } \\
112 \text { genetic variants, } 42 \text { genes, and } 46 \\
\text { PGx-actionable drugs; system had } \\
\text { nearly } 2000 \text { logins in } 43 \text { months since } \\
\text { inception; deployment of GPS } \\
\text { provided a tool that allowed point of } \\
\text { care genomic delivery with high } \\
\text { usability }\end{array}$ \\
\hline $\begin{array}{l}\text { O'Donnell et } \\
\text { al. (2017) }\end{array}$ & $\begin{array}{l}\text { Study the influence of } \\
\text { PGx alerts on } \\
\text { prescribing behaviors }\end{array}$ & $\begin{array}{l}\text { Seventeen providers from } 8 \\
\text { different medicine primary } \\
\text { care and subspecialty clinics } \\
\text { participated in the study }\end{array}$ & $\begin{array}{l}2279 \text { outpatient encounters were } \\
\text { analyzed; high PGx risk medications } \\
\text { were changed more often than } \\
\text { medications lacking PGx information; } \\
\text { medications with cautionary PGx } \\
\text { information also changed more } \\
\text { frequently; PGx information improved } \\
\text { prescribing in patterns aimed at } \\
\text { reducing patient risk }\end{array}$ \\
\hline
\end{tabular}




\section{Chapter 3}

\section{Results}

The healthcare field has experienced numerous technological advances, which have helped improve patient care. The introduction and implementation of EHR systems and CDS systems have helped improve how clinicians provide care to their patients. Scientific discoveries in the pharmacogenomic fields have helped scientists understand how medications may effect patients differently. Implementing pharmacogenomic information into EHR and CDS systems could potentially help providers appropriately prescribe certain medications and reduce the risk of adverse events. The articles from this literature review discuss various topics related to pharmacogenomics and EHR and CDS systems.

Ubanyionwu et al studied prescribers' responses to CDS alerts designed to prompt Smethyltransferase (TPMT), which is an enzyme, genetic testing. There are several medications, such as azathioprine, mercaptopurine, and thioguanine, that are inactivated by TPMT. Low TPMT activity can lead to an accumulation of the active metabolites of these medications and increased risk of toxicities. This is the reason scientists are advocating for preemptive TPMT genetic testing before starting therapy with these agents. The authors conducted a single-center, retrospective chart review to evaluate prescriber response to the TPMT genetic testing alert. The healthcare institution had implemented CDS alerts that were designed to fire when a prescriber ordered thiopurine. The studied found that during the study period, 500 CDS alerts were generated, and TPMT testing was ordered in only $20 \%$ of the cases; in $80 \%$ of the cases, testing was not ordered. The study found that a large number of alerts were neglected due to poor alerting accuracy and alert fatigue. The authors also discovered that there was limited use of online thiopurine doses by prescribers. The authors indicated that pharmacogenomic CDS 
enables clinicians to identify patients at risk for adverse reactions due to medications such as thiopurine. This will help improve prescribing practices in the future.

A study by Caraballo et al developed a study to overcome technical and clinical challenges associated with implementing pharmacogenomic data. The investigators organized the implementation into eight independent components addressing "resources, governance, clinical practice, education, testing, knowledge translation, clinical decision support (CDS), and maintenance" (Caraballo et al., 2017). This study was conducted at the Mayo Clinic, which is a large academic medical center. During the study period, the researchers reviewed 21 specific drug-gene interactions, and implemented 18 of those into the EHR system as pharmacogenomicCDS interventions. They found complete adherence to the model, but variable production and delay time. The researchers observed prescriber resistance to provide approval due to limited literature to support implement pharmacogenomic testing. The study had a total of 1,247 providers that interacted with the pharmacogenomic CDS system during the study period, and they observed that interventions were triggered for 3,788 unique patients. They also implemented education resources to complement the drug-gene interactions to provide clinicians additional resources. The authors concluded that a comprehensive model can support pharmacogenomic implementation, but there are challenges that need to be addressed and overcome to expand the usage of pharmacogenomics data.

Hicks et al described a pharmacist-managed pharmacogenomic services within a large health system. The investigators used the Clinical Pharmacogenetics Implementation Consortium (CPIC) guidelines for several drug-gene pairs and developed custom rules and alerts that were implemented into an EHR system to provide pharmacogenomic CDS. The study was conducted at the Cleveland Clinic Health System. They found that integrating 3 gene-drug pairs over a 3- 
month study period, they identified 17 patients at risk for severe adverse reactions. The investigators found that clinicians recommended a pharmacogenomics consultation service to address questions that are not gathered by CDS or data-mining services. These alerts subsequently resulted in a change in the prescribing of the medication therapy to help reduce the risk of adverse events in patients.

A study was conducted to outline the implementation of a comprehensive clinical pharmacogenomics service in a pediatric hospital and the integration of CDS in the EHR. Manzi et al describe how clinical decision support based on documented pharmacogenomic variant status in EHR plays a role in ordering and dispensing medication. They found that CDS rules built in the EHR provided guidance to healthcare providers for 31 patients with actionable pharmacogenomic variant. The researchers concluded that if pharmacogenomic data is incorporated into CDS properly, there is potential to impact incidence of adverse drug events.

A study by St Sauver et al was conducted to survey primary care clinicians' response to integration of pharmacogenomic CDS alerts in the EHR. The investigators sent surveys to clinicians in the Mayo Clinic Primary Care Practice. The goals of the surveys was to analyze the clinicians' perception of implementation of pharmacogenomics and whether they thought this would be useful in their practice. From the survey, they found that $52 \%$ of the providers did not expect or did not know whether they would use pharmacogenomic information in future prescribing practices. They also found that approximately $53 \%$ of the clinicians felt that the alerts were confusing, frustrating, irritating, and it was not easy to find additional information regarding the alert. Investigators reported that only $30 \%$ of the clinicians made a change in their prescribing practice due to a CDS alert. The authors concluded that there was lack of clinician comfort with integration of pharmacogenomic data into primary care and the pharmacogenomic 
CDS systems need to be user-friendly.

Nishimura et al set out to create a CDS system that incorporates pharmacogenomic data. The investigators programmed CDS rules using machine-readable incidental findings into an EHR system. They created alerts for 48 actionable pharmacogenomic variants in 11 genes. The authors concluded that incidental findings could possibly be used to create CDS alerts, however, tremendous resources are required to ensure that alerts are consistent with updated pharmacogenomic literature.

Another study led by Nishimura with another group studied physician opinions on CDS alerts for pharmacogenomic drug-gene interaction alerts and whether those alerts are useful to them in their practice. They invited 52 physicians to participate in a simulation and a survey which involved a CDS alert for clopidogrel and CYP2C10 drug-gene interaction. They found that only $4 \%$ of the participants reported that they would override the alert. Approximately $92 \%$ of the participants felt that the alerts were useful. The researchers concluded that many physicians were open to pharmacogenomic CDS alerts, especially when they are user-friendly and placed appropriately in the prescribing process.

Overby et al developed a study to investigate the clinical impact of using a CDS system embedded in an EHR system to provide pharmacogenomic information to prescribers. The investigators recruited 22 physicians to participate in the study. The study found that approximately $83 \%$ of the participants found an advantage to using pharmacogenomic CDS system before the study, and that number increased to $94 \%$ at the end of the study. The researchers concluded that the pharmacogenomic CDS system needs to be user-friendly and there needs to be a focus on content delivery, content, and tailoring to prescriber characteristics. A computerized physician order entry (CPOE) system with pharmacogenomic CDS alerts 
was evaluated by Devine et al. They recruited a group of cardiologists and oncologists and presented them with five hypothetical clinical case scenarios. The scenarios included a drug-gene pair that would require dosage adjustment consideration. The participants reported that pharmacogenomic data is important for prescribing decisions, however, the information needs to be shown in a useful manner. The authors concluded that prescribers are more likely to incorporate pharmacogenomic CDS when the information is presented in a user-friendly manner.

Rosenman et al explored the challenges associated with implementing new programs to support precision medicine. In this descriptive study, the authors investigated the process of implementing a pharmacogenomic program at a hospital and its outpatient clinics. The study included 14 genes and 27 medications. The researchers discovered that some of the challenges included clinician education and changes in standards of care, integrating pharmacogenomics into EHR systems, and patient education and participation in the decision-making process. The authors drew a conclusion that pharmacogenomics CDS has strong potential to improv health care, but the challenges that are present need to be tackled to be able to utilize this valuable tool.

Caraballo et al published a brief article in which they integrated CDS alerts in an EHR system for the gene encoding CYP2D6. They created a series of CDS rules to alerts providers based on the results of pharmacogenomic testing for CYP2D6 and the documented genotypes and phenotypes in the EHR. The CDS alerts fired for high or low activity of this gene. The alerts also linked providers to additional pharmacogenomic education and alternative treatment options if there were any available. During the study period, there were a total of 206 events that were triggered by the CPOE system. They found that approximately $75 \%$ of the alerts were displayed due to increased activity and approximately $25 \%$ due to decreased activity. They also found that some alerts were displayed multiple times for the same drug/patient/provider interaction. The 
authors found that integrating CDS alerts into an EHR system is plausible, however, there significant challenges. Clinicians need to be provided with education to understand these alerts and prevent unnecessary and repetitive alerts.

A group of investigators, Danahey et al, built and designed a genomic prescribing system. The investigators documented that a big implementation challenge lies in incorporating clinically actionable genomic data in the EHR system. The goal of this project was to build a system that was user-friendly and allowed the system to incorporate complex genomic data. They had incorporated 257 CDS alerts, which included 112 genetic variants, 42 genes, and 46 pharmacogenomic actionable drugs. The CDS alerts presented users with three different colors to denote the risk for each genomic result. The system had 2000 logins in 43 months. The authors concluded that a user-friendly genomic prescribing tool allowed enabled point-of-care genomic delivery with high rate of use. 


\section{Chapter 4}

\section{Discussion}

The articles that were selected for this review touched upon various topics related to pharmacogenomics implementation into EHR and CDS systems. Many of the articles discussed implementing a new pharmacogenomic CDS system within an EHR and evaluating clinician interaction with these systems. The studies revealed that they were able to implement these systems, however, they learned that there are many challenges that came to light during this process. They needed to find solutions for these complications to make the system better.

There were many challenges that were reported in this studies. The common issues that came up in these studies were lack of prescriber knowledge of pharmacogenomics and how it would impact their prescribing practices. Some prescribers were able to see benefits in their prescribing practice after they had participated in the study. The studies also found that users of these systems wanted a user-friendly interface that provided the necessary information in the prescribing process. The participants also wanted the system to provide them with additional information regarding the specific alert and alternative medication if it is available.

The studies noted that there is potential for pharmacogenomics to decrease adverse drug reactions and improve drug efficacy, however, there are several challenges that have kept the incorporation rate slow. The challenges include reimbursement for genetic testing, developing an infrastructure and standardized process to store, access, and interpret genomic data, and clinician hesitation regarding the clinical and financial benefits of pharmacogenomics guided treatment regimen. There is concern that the current EHR and CDS tools may not be able to handle the influx of genomic data that is anticipated in the future, which means that additional infrastructure will be required. A comprehensive strategy that incorporates all aspects of pharmacogenomic 
driven medicine, starting from the laboratory to data migration and clinical involvement to multidisciplinary governance is required to tackle this challenge.

Institutions are starting to realize the benefits of implementing pharmacogenomic CDS into their EHR system. They have learned that they can improve patient care if they incorporate such system. There are challenges that need to be overcome when implementing these systems. There are a lack of studies that evaluate the impact of pharmacogenomic CDS systems and the true clinical impact is unclear. Many of the studies that are published only provide a short-term impact of the pharmacogenomic CDS. Majority of the pharmacogenomic implementations are currently limited to large academic medical centers. There is still a need for clinician-friendly pharmacogenomic CDS systems and more research needs to be conducted on this topic. 


\section{Chapter 5}

\section{Conclusion and Recommendations}

Medical science is advancing at rapid pace and many new technologies are being utilized to provide better care for patients. Numerous institutions have made extensive efforts to implement pharmacogenomic CDS in clinical practice, however, they have faced many challenges along the way, and the true clinical impact is unclear. The majority of the current pharmacogenomic implementations have occurred in academic medical centers, which does not provide a clear view of the impact of such system in other traditional healthcare institutions. If institutions are able to implement user-friendly pharmacogenomic CDS integrated into an EHR system, it has the potential to support pharmacogenomic driven medicine, which will help reduce adverse drug reactions and improve therapeutic efficacy of the treatment regimen a patient receives. There is a lack of published literature on this topic.

This literature search was extensive; however, another literature search should be conducted to ensure that all studies that are related to this article are identified. Other search terms that could potentially be incorporated in the search are computerized physician order entry system and health information technology. Researchers need to conduct extensive studies to truly identify the clinical impact of implementing pharmacogenomic CDS integrated into an EHR system. These types of studies will help discover the true benefits of pharmacogenomic CDS and aid in brining changes to the current standard of patient care. 


\section{References}

Caraballo, P. J., et al. (2015). Clinical Decision Support to Implement CYP2D6 Drug-Gene Interaction. Stud Health Technol Inform, 216, 946.

Caraballo, P. J., et al. (2017). Multidisciplinary model to implement pharmacogenomics at the point of care. Genet Med, 19(4), 421-429. doi:10.1038/gim.2016.120

Danahey, K., et al. (2017). Simplifying the use of pharmacogenomics in clinical practice: Building the genomic prescribing system. J Biomed Inform, 75, 110-121. doi:10.1016/j.jbi.2017.09.012

Devine, E. B., et al. (2014). Usability evaluation of pharmacogenomics clinical decision support aids and clinical knowledge resources in a computerized provider order entry system: a mixed methods approach. Int J Med Inform, 83(7), 473-483. doi:10.1016/j.ijmedinf.2014.04.008

Hicks, J. K., et al. (2016). Implementation of Clinical Pharmacogenomics within a Large Health System: From Electronic Health Record Decision Support to Consultation Services. Pharmacotherapy, 36(8), 940-948. doi:10.1002/phar.1786

HIMSS. (2014). What is Health Informatics? Retrieved March 5, 2019 from http://www.himss.org/health-informatics-defined

Klein, M. E., et al. (2017). Clinical Implementation of Pharmacogenomics for Personalized Precision Medicine: Barriers and Solutions. J Pharm Sci, 106(9), 2368-2379. doi:10.1016/j.xphs.2017.04.051

Ko, T.-M., et al. (2016). Pharmacogenomics for personalized pain medicine. Acta Anaesthesiologica Taiwanica, 54(1), 24-30. doi:https://doi.org/10.1016/j.aat.2016.02.001

Manzi, S. F., et al. (2017). Creating a scalable clinical pharmacogenomics service with automated interpretation and medical record result integration - experience from a pediatric tertiary care facility. J Am Med Inform Assoc, 24(1), 74-80. doi:10.1093/jamia/ocw052

NIH. (2018). What is the Human Genome Project? Retrieved April 2, 2019 from https://www.genome.gov/human-genome-project/What

NIH. (2019). What is pharmacogenomics? Retrieved April 10, 2019 from https://ghr.nlm.nih.gov/primer/genomicresearch/pharmacogenomics

Nishimura, A. A., et al. (2015). Development of clinical decision support alerts for pharmacogenomic incidental findings from exome sequencing. Genet Med, 17(11), 939-942.

doi:10.1038/gim.2015.5 
Nishimura, A. A., et al. (2016). Physician perspectives of CYP2C19 and clopidogrel drug-gene interaction active clinical decision support alerts. Int J Med Inform, 86, 117-125. doi:10.1016/j.ijmedinf.2015.11.004

O'Donnell, P. H., et al. (2017). Pharmacogenomics-Based Point-of-Care Clinical Decision Support Significantly Alters Drug Prescribing. Clin Pharmacol Ther, 102(5), 859-869. doi:10.1002/cpt.709

Overby, C. L., et al. (2015). Making pharmacogenomic-based prescribing alerts more effective: A scenario-based pilot study with physicians. J Biomed Inform, 55, 249-259. doi:10.1016/j.jbi.2015.04.011

Rosenman, M. B., et al. (2017). Lessons Learned When Introducing Pharmacogenomic Panel Testing into Clinical Practice. Value Health, 20(1), 54-59. doi:10.1016/j.jval.2016.08.727

Schatz, S. N., \& Weber, R. J. (2015). Adverse drug reactions. ACCP (American College of Clinical Pharmacy). CNS. Pharmacy Practice, PSAP.

St Sauver, J. L., et al. (2016). Integrating Pharmacogenomics into Clinical Practice: Promise vs Reality. Am J Med, 129(10), 1093-1099.e1091. doi:10.1016/j.amjmed.2016.04.009

Ubanyionwu, S., et al. (2018). Evaluation of prescriber responses to pharmacogenomics clinical decision support for thiopurine S-methyltransferase testing. Am J Health Syst Pharm, 75(4), 191-198. doi:10.2146/ajhp170280 


\section{Appendix 1}

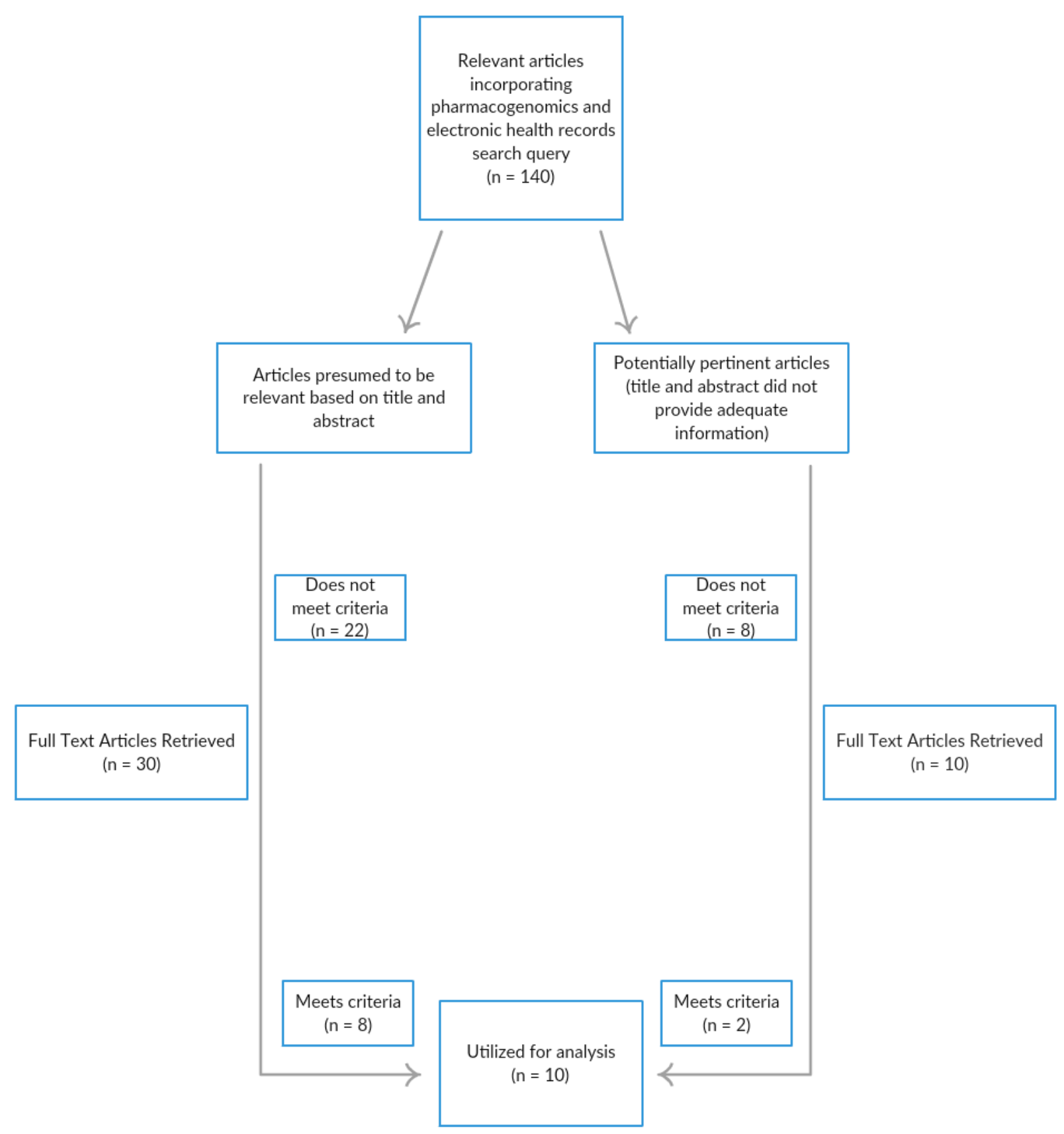

Figure 1: Initial search query which included the search terms electronic health records, medical records system, and pharmacogenomics. 


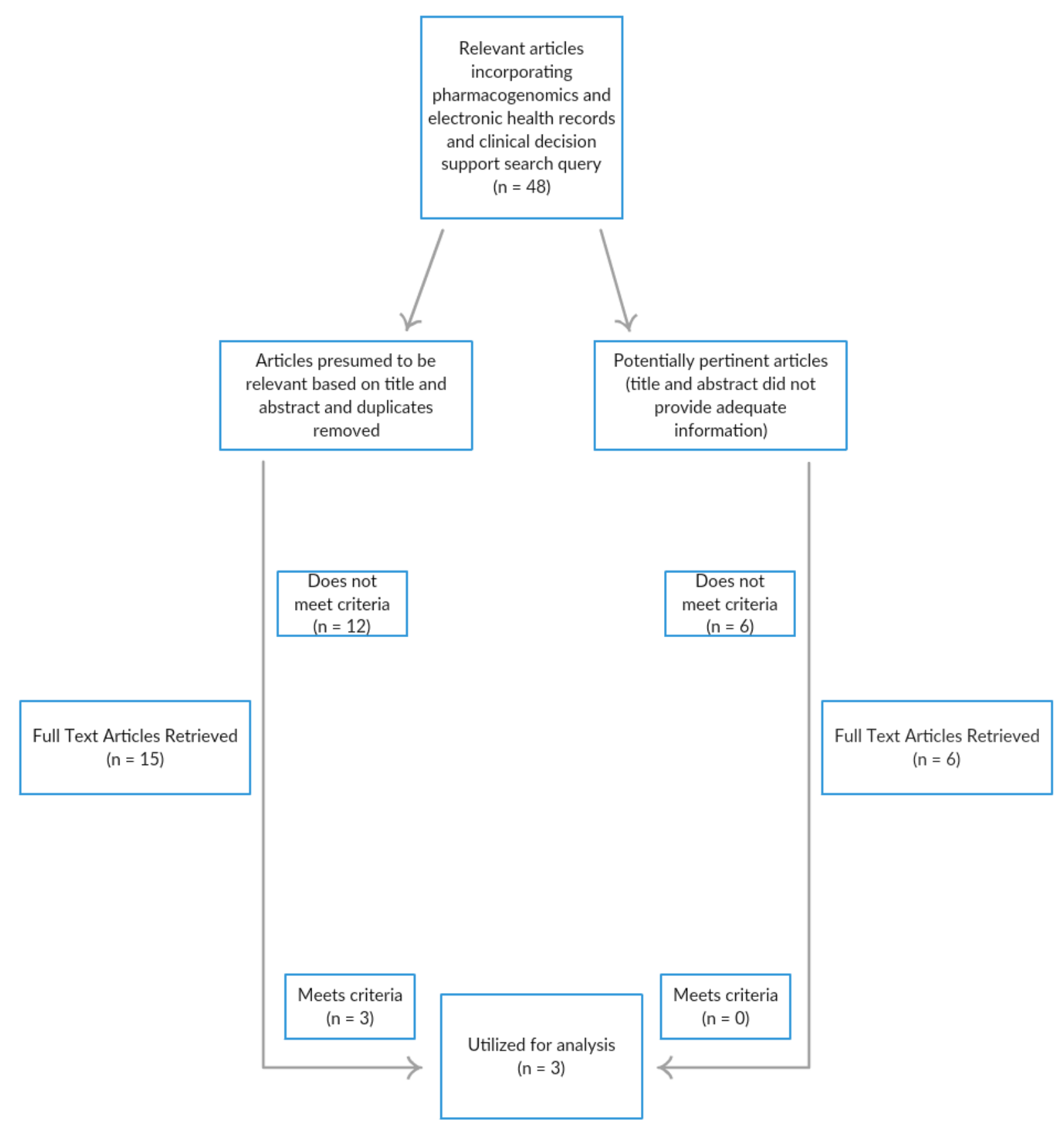

Figure 2: Second search query which included the search terms electronic health records, medical records system, and pharmacogenomics, clinical decision support. 


\section{Appendix 2}

\begin{tabular}{|c|c|c|}
\hline Database & Search Query & Results \\
\hline \multirow[b]{2}{*}{ PubMed } & $\begin{array}{l}\text { (((("Electronic Health Records"[Mesh] OR "Electronic Health Records" OR } \\
\text { "Electronic Health Record" OR "Electronic Medical Records" OR } \\
\text { "Electronic Medical Record" OR "Computerized Medical Record" OR } \\
\text { "Computerized Medical Records")) AND ("Medical Records Systems, } \\
\text { Computerized"[Mesh] OR "Medical Record Systems" OR "Computerized } \\
\text { Patient Medical Records" OR "Automated Medical Records System" OR } \\
\text { "Automated Medical Record System" OR "Computerized Medical Record } \\
\text { System" OR "Computerized Medical Records System" OR "Computerized } \\
\text { Medical Record Systems" OR "Computerized Medical Records Systems" } \\
\text { OR "Automated Medical Record System" OR "Automated Medical Record } \\
\text { Systems"))) AND ("Pharmacogenetics"[Mesh] OR "Pharmacogenetics" OR } \\
\text { "Pharmacogenomics" OR "Pharmacogenomic") }\end{array}$ & 65 \\
\hline & $\begin{array}{l}\text { (((((("Medical Records Systems, Computerized"[Mesh] OR "Medical } \\
\text { Records Systems, Computerized" OR "Automated Medical Records } \\
\text { System" OR "Medical Record System, Automated" OR "Medical Record } \\
\text { Systems, Automated" OR "Medical Records System, Automated" OR } \\
\text { "Medical Records Systems, Automated" OR "Automated Medical Records } \\
\text { Systems" OR "Computerized Medical Record System" OR "Computerized } \\
\text { Medical Record Systems" OR "Computerized Medical Records System" OR } \\
\text { "Medical Record System, Computerized" OR "Medical Record Systems, } \\
\text { Computerized" OR "Medical Records System, Computerized" OR } \\
\text { "Computerized Medical Records Systems" OR "Automated Medical Record } \\
\text { System" OR "Automated Medical Record Systems"))) AND ("Electronic } \\
\text { Health Records"[Mesh] OR "Electronic Health Records" OR "Electronic } \\
\text { Medical Records" OR "Electronic Medical Record" OR "Medical Record, } \\
\text { Electronic" OR "Medical Records, Electronic" OR "Record, Electronic } \\
\text { Medical" OR "Records, Electronic Medical" OR "Electronic Health Record" } \\
\text { OR "Health Record, Electronic" OR "Health Records, Electronic" OR } \\
\text { "Record, Electronic Health" OR "Records, Electronic Health" OR "Medical } \\
\text { Records, Computerized" OR "Medical Record, Computerized" OR } \\
\text { "Computerized Medical Record" OR " Record, Computerized Medical" OR } \\
\text { "Records, Computerized Medical" OR "Computerized Medical Records"))) } \\
\text { AND ("Decision Support Systems, Clinical"[Mesh] OR "Decision Support } \\
\text { Systems, Clinical" OR "Clinical Decision Support Systems" OR "Clinical } \\
\text { Decision Support" OR "Clinical Decision Supports" OR "Decision } \\
\text { Supports, Clinical" OR "Support, Clinical Decision" OR "Supports, Clinical } \\
\text { Decision" OR "Decision, Support, Clinical"))) AND } \\
\text { ("Pharmacogenetics"[Mesh] OR "Pharmacogenetics" OR } \\
\text { "Pharmacogenetic" OR "Pharmacogenomic" OR "Pharmacogenomics") }\end{array}$ & 31 \\
\hline Scopus & $\begin{array}{c}\text { ((("Electronic Health Records" OR "Electronic Health Records" OR } \\
\text { "Electronic Health Record" OR "Electronic Medical Records" OR }\end{array}$ & 81 \\
\hline
\end{tabular}




\begin{tabular}{|c|c|c|}
\hline & $\begin{array}{c}\text { "Electronic Medical Record" OR "Computerized Medical Record" OR } \\
\text { "Computerized Medical Records")) AND ("Medical Records Systems, } \\
\text { Computerized" OR "Medical Record Systems" OR "Computerized Patient } \\
\text { Medical Records" OR "Automated Medical Records System" OR } \\
\text { "Automated Medical Record System" OR "Computerized Medical Record } \\
\text { System" OR "Computerized Medical Records System" OR "Computerized } \\
\text { Medical Record Systems" OR "Computerized Medical Records Systems" } \\
\text { OR "Automated Medical Record System" OR "Automated Medical Record } \\
\text { Systems"))) AND ("Pharmacogenetics" OR "Pharmacogenetics" OR } \\
\text { "Pharmacogenomics" OR "Pharmacogenomic") }\end{array}$ & \\
\hline & $\begin{array}{l}\text { (((((("Medical Records Systems, Computerized" OR "Medical Records } \\
\text { Systems, Computerized" OR "Automated Medical Records System" OR } \\
\text { "Medical Record System, Automated" OR "Medical Record Systems, } \\
\text { Automated" OR "Medical Records System, Automated" OR "Medical } \\
\text { Records Systems, Automated" OR "Automated Medical Records Systems" } \\
\text { OR "Computerized Medical Record System" OR "Computerized Medical } \\
\text { Record Systems" OR "Computerized Medical Records System" OR } \\
\text { "Medical Record System, Computerized" OR "Medical Record Systems, } \\
\text { Computerized" OR "Medical Records System, Computerized" OR } \\
\text { "Computerized Medical Records Systems" OR "Automated Medical Record } \\
\text { System" OR "Automated Medical Record Systems"))) AND ("Electronic } \\
\text { Health Records" OR "Electronic Health Records" OR "Electronic Medical } \\
\text { Records" OR "Electronic Medical Record" OR "Medical Record, } \\
\text { Electronic" OR "Medical Records, Electronic" OR "Record, Electronic } \\
\text { Medical" OR "Records, Electronic Medical" OR "Electronic Health Record" } \\
\text { OR "Health Record, Electronic" OR "Health Records, Electronic" OR } \\
\text { "Record, Electronic Health" OR "Records, Electronic Health" OR "Medical } \\
\text { Records, Computerized" OR "Medical Record, Computerized" OR } \\
\text { "Computerized Medical Record" OR " Record, Computerized Medical" OR } \\
\text { "Records, Computerized Medical" OR "Computerized Medical Records"))) } \\
\text { AND ("Decision Support Systems, Clinical" OR "Decision Support } \\
\text { Systems, Clinical" OR "Clinical Decision Support Systems" OR "Clinical } \\
\text { Decision Support" OR "Clinical Decision Supports" OR "Decision } \\
\text { Supports, Clinical" OR "Support, Clinical Decision" OR "Supports, Clinical } \\
\text { Decision" OR "Decision, Support, Clinical"))) AND ("Pharmacogenetics" } \\
\text { OR "Pharmacogenetics" OR "Pharmacogenetic" OR "Pharmacogenomic" } \\
\quad \text { OR "Pharmacogenomics") } \\
\end{array}$ & 1 \\
\hline $\begin{array}{l}\text { Web of } \\
\text { Science }\end{array}$ & $\begin{array}{l}\text { (((("Electronic Health Records" OR "Electronic Health Records" OR } \\
\text { "Electronic Health Record" OR "Electronic Medical Records" OR } \\
\text { "Electronic Medical Record" OR "Computerized Medical Record" OR } \\
\text { "Computerized Medical Records")) AND ("Medical Records Systems, } \\
\text { Computerized" OR "Medical Record Systems" OR "Computerized Patient } \\
\text { Medical Records" OR "Automated Medical Records System" OR } \\
\text { "Automated Medical Record System" OR "Computerized Medical Record } \\
\text { System" OR "Computerized Medical Records System" OR "Computerized }\end{array}$ & 1 \\
\hline
\end{tabular}




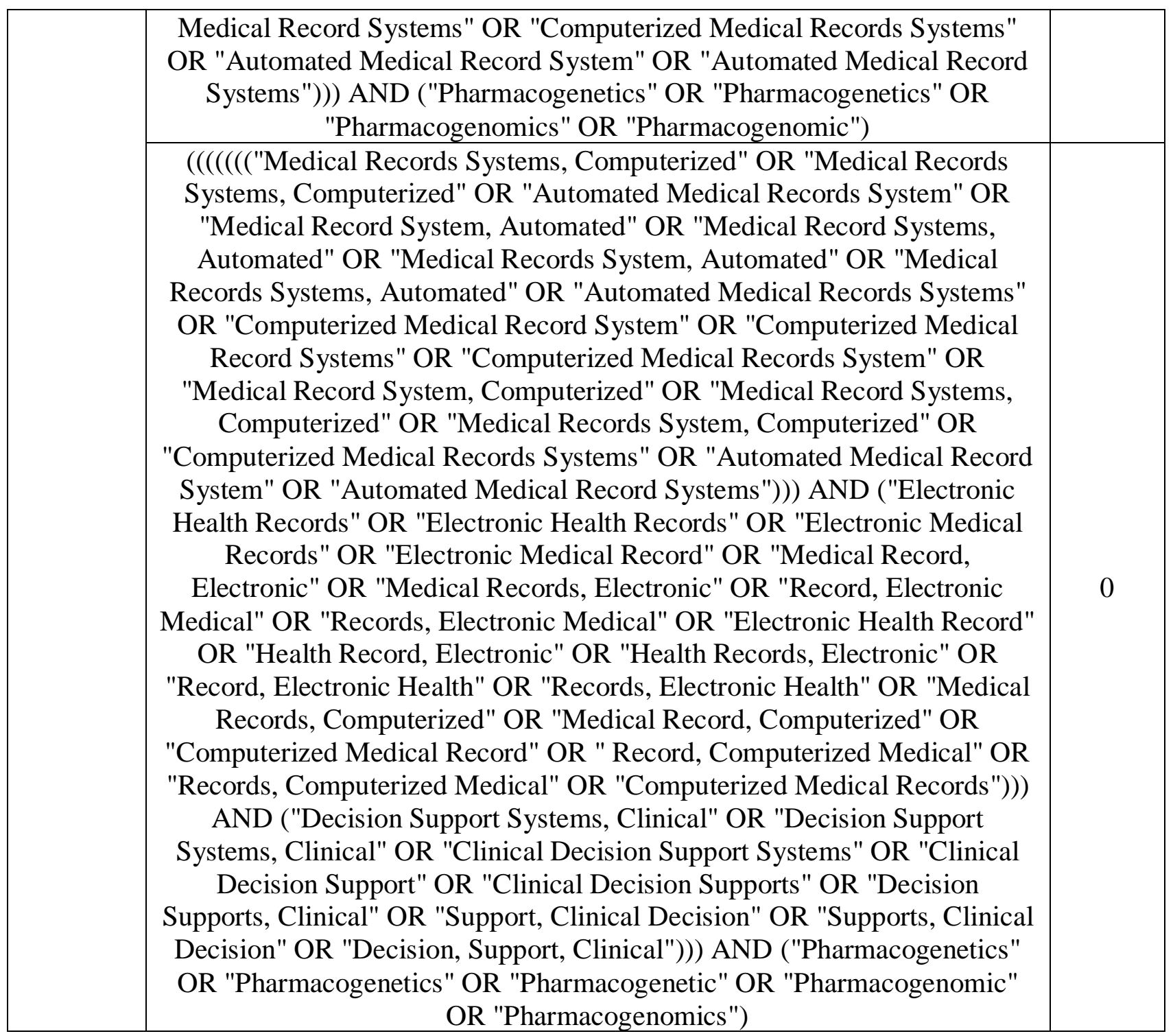

